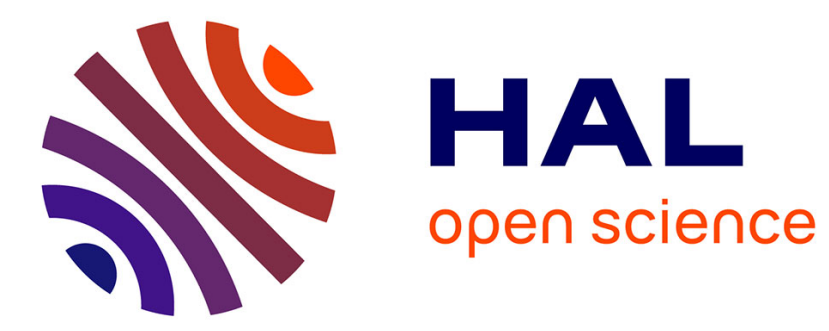

\title{
Management of serious meticillin-resistant infections: what are the limits?
}

Ian M. Gould, Roberto Cauda, Silvano Esposito, Francesco Gudiol, Teresita Mazzei, Javier Garau

\section{- To cite this version:}

Ian M. Gould, Roberto Cauda, Silvano Esposito, Francesco Gudiol, Teresita Mazzei, et al.. Management of serious meticillin-resistant infections: what are the limits?. International Journal of Antimicrobial Agents, 2011, 37 (3), pp.202. 10.1016/j.ijantimicag.2010.10.030 . hal-00671244

\section{HAL Id: hal-00671244 \\ https://hal.science/hal-00671244}

Submitted on 17 Feb 2012

HAL is a multi-disciplinary open access archive for the deposit and dissemination of scientific research documents, whether they are published or not. The documents may come from teaching and research institutions in France or abroad, or from public or private research centers.
L'archive ouverte pluridisciplinaire HAL, est destinée au dépôt et à la diffusion de documents scientifiques de niveau recherche, publiés ou non, émanant des établissements d'enseignement et de recherche français ou étrangers, des laboratoires publics ou privés. 


\section{Accepted Manuscript}

Title: Management of serious meticillin-resistant

Staphylococcus aureus infections: what are the limits?

Authors: Ian M. Gould, Roberto Cauda, Silvano Esposito, Francesco Gudiol, Teresita Mazzei, Javier Garau

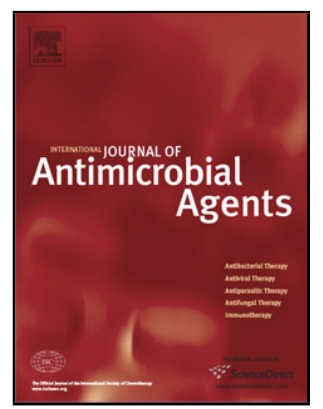

PII:

S0924-8579(10)00532-7

DOI: doi:10.1016/j.ijantimicag.2010.10.030

Reference: ANTAGE 3489

To appear in: International Journal of Antimicrobial Agents

Received date: $\quad 29-10-2010$

Accepted date: $\quad 29-10-2010$

Please cite this article as: Gould IM, Cauda R, Esposito S, Gudiol F, Mazzei T, Garau J, Management of serious meticillin-resistant Staphylococcus aureus infections: what are the limits?, International Journal of Antimicrobial Agents (2010), doi:10.1016/j.ijantimicag.2010.10.030

This is a PDF file of an unedited manuscript that has been accepted for publication. As a service to our customers we are providing this early version of the manuscript. The manuscript will undergo copyediting, typesetting, and review of the resulting proof before it is published in its final form. Please note that during the production process errors may be discovered which could affect the content, and all legal disclaimers that apply to the journal pertain. 


\section{Management of serious meticillin-resistant Staphylococcus aureus infections: what are the limits? ${ }^{\text {* }}$}

Ian M. Gould ${ }^{\mathrm{a}, \star}$, Roberto Cauda ${ }^{\mathrm{b}}$, Silvano Esposito ${ }^{\mathrm{c}}$, Francesco Gudiol ${ }^{\mathrm{d}}$, Teresita Mazzei $^{\mathrm{e}}$, Javier Garau ${ }^{\dagger}$

${ }^{a}$ Department of Medical Microbiology, Aberdeen Royal Infirmary, Foresterhill, Aberdeen AB25 2ZN, UK

${ }^{\mathrm{b}}$ Departments of Infectious Diseases, Microbiology, Gerontology, and Intensive Care and Anesthesiology, Università Cattolica del Sacro Cuore, Rome, Italy

${ }^{c}$ Department of Infectious Diseases, Second University of Naples, Naples, Italy

d Service of Infectious Diseases, Hospital Universitari de Bellvitge, Barcelona, Spain

e Department of Preclinical and Clinical Pharmacology, University of Florence, Florence, Italy

${ }^{\dagger}$ Department of Medicine, Hospital Universitari Mútua de Terrassa, Terrassa, Barcelona, Spain

ARTICLE INFO

Article history:

Received 29 October 2010

Accepted 29 October 2010

Keywords:

MRSA treatment 
$14 / 05 / 2010$

Antibiotics

MIC drift

* Corresponding author. Tel.: +44 1224554 954; fax. +44 1224550632.

E-mail address: i.m.gould@abdn.ac.uk (I.M. Gould).

* This review is based on the proceedings of an expert panel meeting jointly held by the European Society of Clinical Microbiology and Infectious Diseases (ESCMID) and the International Society of Chemotherapy (ISC), 6-7 March 2010, Rome, Italy. 
$14 / 05 / 2010$

\section{ABSTRACT}

Severe (life-threatening) meticillin-resistant Staphylococcus aureus (MRSA) infection continues to be treated with vancomycin despite accumulating evidence of poor outcome, increasing resistance and unachievable pharmacokinetic/pharmacodynamic (PK/PD) targets. The minimum inhibitory concentration (MIC) susceptibility breakpoint for vancomycin was recently reduced to $2 \mathrm{mg} / \mathrm{L}$. Whilst the great majority of clinical isolates are thus still classified as susceptible, the available clinical evidence argues for a method-dependent breakpoint of $0.5 \mathrm{mg} / \mathrm{L}$ (broth dilution) or $1.0 \mathrm{mg} / \mathrm{L}$ (Etest), which would classify many strains as resistant, or at best intermediate. However, automated susceptibility testing systems are not currently capable of performing accurately at this low level, and such low breakpoints are unsatisfactory because the poor reproducibility of tests (plus or minus one doubling dilution) results in a critical non-reproducibility around the modal MIC of $1 \mathrm{mg} / \mathrm{L}$ described in most published data. Therefore, vancomycin should be used with caution in severe (life-threatening) staphylococcal disease and the MIC should always be reported by method. Daptomycin is generally preferred for bacteraemia/endocarditis and linezolid for pneumonia. Better outcome data for vancomycin, based on achievable PK/PD targets and using robust MIC tests, are urgently required. 


\section{Introduction}

The reported prevalence rates of meticillin-resistant Staphylococcus aureus (MRSA) have decreased or stabilised over recent years in many European countries. However, MRSA proportions still exceed $10 \%$ in 24 participating countries within the European Antimicrobial Resistance Surveillance System (EARSS) and exceed 25\% in 11 countries [1]. Moreover, accumulating data indicate that MRSA infections are associated with a worse prognosis than meticillin-susceptible S. aureus (MSSA) infections [2-5]. Severe healthcare-associated MRSA infections, namely bacteraemia, hospital-acquired pneumonia (HAP) and ventilator-associated pneumonia (VAP), are associated with a particularly high risk of mortality and complications. Optimal therapy for these infections remains a therapeutic challenge.

This review is based on the proceedings of an expert panel meeting jointly sponsored by the European Society of Clinical Microbiology and Infectious Diseases (ESCMID) and the International Society of Chemotherapy (ISC) that took place in Rome, Italy, on the 6-7 March 2010. This paper adds to and updates a previous MRSA Consensus Conference statement sponsored by ESCMID [6]. In particular, key questions addressed by the present paper are:

- is vancomycin still appropriate first-line therapy for severe, life-threatening MRSA infections?

- are the current clinical breakpoints for vancomycin appropriate and, if not, where should they be set?

- what roles do daptomycin and linezolid have in this setting? and 
14/05/2010

- what are the key areas for future research?

\section{Vancomycin}

Vancomycin has long been regarded as the standard option for initial treatment for severe MRSA infections. More recently, some note of caution has started to be expressed, in particular when sepsis is severe/life-threatening [bacteraemia/endocarditis, VAP or the organism has a raised minimum inhibitory concentration (MIC)]. Recent reviews recommend vancomycin for sepsis that is not life-threatening and for infections caused by organisms for which the vancomycin MIC is $\leq 1 \mathrm{mg} / \mathrm{L}$ or is unknown [6]. However, use of the MIC test to direct therapy is variable. A recent survey of UK microbiologists regarding the management of $S$. aureus bacteraemia found that only one-third routinely monitor MICs [7]. Empirically, vancomycin is presently recommended for initial treatment of suspected severe $S$. aureus infections in healthcare settings with an increased incidence of MRSA or when other risk factors for MRSA infections are present [6].

Vancomycin has a number of well recognised limitations that have prompted its role to be questioned $[8,9]$. Vancomycin shows poor cidality and clinical efficacy against serious MSSA infections. Hence, empirical use of vancomycin for a severe S. aureus infection that proves to be caused by MSSA leaves patients at risk of a poor outcome. Vancomycin has a narrow therapeutic index and is nephrotoxic at high doses, necessitating therapeutic drug monitoring. The agent also shows withinpatient pharmacokinetic variability and poor penetration into lung epithelial fluid. There is some evidence from retrospective subgroup analyses that vancomycin is 
suboptimal for the treatment of MRSA pneumonia $[10,11]$. There is also evidence of a gradual decrease in vancomycin susceptibility among MRSA isolates, i.e. an MIC 'creep'.

\subsection{Minimum inhibitory concentration creep}

Vancomycin resistance remains rare. Overall, 11 vancomycin-intermediate $S$. aureus (VISA) and 2 vancomycin-resistant $S$. aureus (VRSA) were reported to the EARSS database in 2008 [1]. However, some surveillance studies have reported increases in vancomycin MICs within the defined limits of susceptibility. Single-centre longitudinal studies in the USA found that the modal MIC, assessed by broth microdilution (BMD) or Etest, rose from $0.5 \mathrm{mg} / \mathrm{L}$ or $0.75 \mathrm{mg} / \mathrm{L}$ to $1 \mathrm{mg} / \mathrm{L}$ between 2000 and 2005 [12,13]. Similarly, modal MICs (by BMD) of 0.75-1 mg/L were reported by surveillance studies of MRSA isolates collected from hospitals in the USA and UK between 1999 and 2006 [14-17].

Heterogeneous VISA (hVISA) strains have a small subpopulation of cells, typically $10^{5}-10^{6}$ colony-forming units, able to grow at a vancomycin concentration of $4 \mathrm{mg} / \mathrm{L}$. A laborious technique designated population analysis profile (PAP) is required for confirmation. A correlation between increased vancomycin MICs and the emergence of hVISA has been reported, since up to $50 \%$ of MRSA isolates with vancomycin MICs of $2 \mathrm{mg} / \mathrm{L}$ were found to be hVISA by the PAP method [18]. However, hVISA isolates may have vancomycin MICs within the susceptible range $(0.5-1 \mathrm{mg} / \mathrm{L})$. The hVISA phenotype is a precursor of full-blown VISA. 
$14 / 05 / 2010$

In a recent international study of patients with MRSA endocarditis, more than onequarter of the isolates exhibited the hVISA phenotype [19]. The prevalence of hVISA varied significantly with non-clinical factors such as geography. Moreover, hVISAinfected patients had more infective endocarditis (IE) complications, including persistent bacteraemia and congestive heart failure, than patients with vancomycinsusceptible $S$. aureus IE [19]. This association has been previously reported [20-22]. One readily available strain characteristic that may identify bacteria at higher risk for hVISA is the presence of a vancomycin MIC of $2.0 \mathrm{mg} / \mathrm{L}$. Although only ca. $10 \%$ of the cohort had a vancomycin MIC of $2.0 \mathrm{mg} / \mathrm{L}$ by Etest, $>80 \%$ of these isolates exhibited the hVISA phenotype by PAP testing [19].

However, not all surveillance studies have shown MIC creep over time [14,23,24] and it is possible that the phenomenon could be overestimated by a positive publication bias. There is also geographic heterogeneity, and local increases in MICs may be due to specific clones [24], a factor deserving further research. The poor correlation between BMD and Etest complicates the interpretation of surveillance data. Whilst BMD is a reference method, Etest is widely preferred for routine clinical use. According to data from the USA, the Etest typically gives an MIC one dilution higher than BMD $[16,17]$. Automated testing systems are also widely used but do not accurately detect MICs $<2 \mathrm{mg} / \mathrm{L}$ [25].

Another potential drawback with vancomycin is its effect on subsequent therapy. MRSA bloodstream isolates from patients recently treated with vancomycin may show reduced susceptibility and increased tolerance to vancomycin in vitro [26]. There are some concerns (based on limited evidence) that prior vancomycin 
$14 / 05 / 2010$

exposure in patients who developed glycopeptide-intermediate $S$. aureus (GISA) or heterogeneous GISA may also reduce daptomycin susceptibility [27].

\subsection{Minimum inhibitory concentration breakpoints}

Current MIC breakpoints define vancomycin susceptibility as $\leq 2 \mathrm{mg} / \mathrm{L}[28,29]$. The efficacy of vancomycin is best predicted by the ratio of the area under the 24-h vancomycin concentration-time versus MIC (AUC/MIC) [30]. A value of $>400$ appears to best predict a good outcome both in a neutropenic mouse model and in patients with staphylococcal pneumonia. An increase in the MIC can be expected to reduce the likelihood of attaining the pharmacodynamic target and threaten the efficacy of treatment. Accumulating studies have reported treatment failure when vancomycin was used to treat serious MRSA infections (usually bloodstream infections) with an MIC within the susceptible range, i.e. $>0.5 \mathrm{mg} / \mathrm{L}$ or $1 \mathrm{mg} / \mathrm{L}$ but $\leq 2$ $\mathrm{mg} / \mathrm{L}$ [30-35]. The method used appears to determine the breakpoint, with the reference methods of broth dilution giving a breakpoint of $0.5 \mathrm{mg} / \mathrm{L}$ and the Etest a breakpoint of $1.0 \mathrm{mg} / \mathrm{L}$.

In a prospective cohort study of 414 cases of MRSA bacteraemia, multivariate analysis found that mortality was significantly higher when vancomycin was used empirically for treatment of infections by strains with a vancomycin Etest MIC of 2 mg/L compared with lower MICs [35]. In another prospective cohort study of 95 patients, those with MRSA infections (mostly bacteraemia and respiratory and wound infections) with vancomycin Etest MICs $\geq 2 \mathrm{mg} / \mathrm{L}$ had significantly lower 
$14 / 05 / 2010$

response rates than those with $\mathrm{MICs}<2 \mathrm{mg} / \mathrm{L}$, despite the achievement of target vancomycin trough concentrations (>15 mg/L) [32].

In a retrospective analysis of 30 patients, Sakoulas et al. [31] found that vancomycin was successful in the treatment of $55.6 \%$ of bacteraemia cases where the vancomycin MIC (by agar dilution) was $\leq 0.5 \mathrm{mg} / \mathrm{L}$ and only $9.5 \%$ effective when the MIC was 1-2 mg/L. However, the majority of patients were recruited from studies of patients with bacteraemia refractory to conventional vancomycin therapy. In another retrospective multivariate analysis ( $n=34$ patients), vancomycin was ca. 15 times more likely to fail to eradicate bacteraemia MRSA with a BMD MIC of $2 \mathrm{mg} / \mathrm{L}$ compared with those with an MIC $\leq 1 \mathrm{mg} / \mathrm{L}(P<0.005)$ [33]. Lodise et al. [34] found that patients with vancomycin Etest MICs of $>1.5 \mathrm{mg} / \mathrm{L}$ had a 2.4-fold increase in failure compared with infections with MICs of $<1.0 \mathrm{mg} / \mathrm{L}(36.4 \% \mathrm{vs} .15 .4 \%$, respectively; $P=0.049)$.

It has been suggested that the Clinical and Laboratory Standards Institute (CLSI) BMD testing method used in some studies may be poor at detecting heteroresistance in S. aureus, perhaps owing to a low inoculum [36]. Therefore, limited data support the use of a clinical vancomycin breakpoint of $0.5 \mathrm{mg} / \mathrm{L}$ for broth microdilution (1.0 mg/L for Etest) for the minority of patients with severe MRSA infections. However, there was no clear consensus among the current ESCMID/ISC expert panel on this matter and more data are needed. Surveillance data suggest that a reduction in the breakpoint would render many MRSA strains as vancomycin non-susceptible $[16,17]$. Some data suggest that the higher MICs provided by Etest better predict treatment outcome [36], although further research is required. 


\subsection{Vancomycin dosing}

Some studies reporting suboptimal effectiveness of vancomycin used dosage regimens that were likely to be inadequate, e.g. where target trough concentrations were 8-15 mg/L. Pharmacokinetic/pharmacodynamic (PK/PD) data suggest that a total AUC/MIC of $>400$ is significantly associated with clinical and bacteriological response in MRSA pneumonia [30]. It is recommended that vancomycin is dosed to achieve trough serum concentrations of $15-20 \mathrm{mg} / \mathrm{L}[6,37]$. These levels are considered sufficient to achieve an AUC/MIC of $\geq 400$ in most patients if the MIC is $\leq 1 \mathrm{mg} / \mathrm{L}$ [37]. However, Monte Carlo simulation analysis suggests that even with a trough level of $\geq 15 \mathrm{mg} / \mathrm{L}$, there is only a $60 \%$ likelihood that the clinical PK/PD target will be achieved against MRSA with a vancomycin MIC of $1.0 \mathrm{mg} / \mathrm{L}(100 \%$ for MIC of $0.5 \mathrm{mg} / \mathrm{L}$ and $0 \%$ for MIC of $2 \mathrm{mg} / \mathrm{L}$ ) [9]. Moreover, a retrospective cohort study of patients with MRSA HAP (confirmed by bronchoalveolar lavage cultures) found disappointing evidence of benefit for trough vancomycin concentrations of $\geq 15 \mathrm{mg} / \mathrm{L}$ compared with $<15 \mathrm{mg} / \mathrm{L}$, or for increased vancomycin AUC values [38], although MICs were not measured. Higher trough concentrations (e.g. $\geq 20 \mathrm{mg} / \mathrm{L}$ ) are associated with an increased risk of nephrotoxicity [39]. Therefore, the ESCMID/ISC expert panel continues to recommend that vancomycin should be dosed to achieve a trough level of $15-20 \mathrm{mg} / \mathrm{L}$.

Continuous vancomycin infusion is used instead of intermittent injection in some centres. However, the expert panel considered that there are insufficient data upon which to base recommendations regarding this practice. A loading dose of 
vancomycin is used when the drug is administered by continuous infusion, whereas this is not usually used for intermittent dosing because of the risk of nephrotoxicity with higher vancomycin doses $[39,40]$. However, the lack of a loading dose at the initiation of continuous infusion delays the attainment of therapeutic concentrations for up to $48 \mathrm{~h}$.

In conclusion, vancomycin has important deficiencies and has remained a first-line recommended agent for MRSA infection only because newer agents have not clearly delivered the anticipated advantages, and perhaps because of inertia among physicians. Evidence for an increase in the modal vancomycin MIC, together with PK/PD and clinical data, suggest that comparative studies that established the efficacy of vancomycin $[41,42]$ may be outdated. Most surveyed members of the Infectious Diseases Society of America (IDSA) rejected the proposal that vancomycin was obsolete, whereas the majority of an expert panel accepted this proposal, albeit in many cases with reservations [43]. New comparative studies of vancomycin are required to reassess its efficacy under present conditions and relative to current treatment options. Further PK/PD studies are also required to determine how vancomycin therapy can be optimised in various infection types. Ongoing surveillance is essential to monitor glycopeptide susceptibility patterns. In the meantime, available data support a clinical breakpoint of $0.5 \mathrm{mg} / \mathrm{L}(\mathrm{BMD})$ or 1.0 $\mathrm{mg} / \mathrm{L}$ (Etest), which of course means that many more isolates both of MSSA and MRSA would be classified as resistant or, at best, intermediate.

Specific recommendations regarding the current use of vancomycin are summarised at the end of this article (Table 1). 


\section{Teicoplanin}

According to a recent systematic review of randomised trials involving 2332 patients with various types of infections, teicoplanin was not inferior to vancomycin in terms of all-cause mortality rate [44]. However, this analysis involved few patients with serious infections and underscored the paucity of data regarding the relative efficacy of the two glycopeptides in patients with MRSA infections. Data were available on only 73 patients with MRSA infections from five trials, yielding a relative risk of allcause mortality of 0.67 (95\% confidence interval $0.26-1.72$ ) for vancomycin versus teicoplanin. Some studies have documented an increase in teicoplanin MICs, in common with vancomycin MICs, in MRSA [45].

Teicoplanin has a prolonged half-life [46] and should always be initiated using a loading dose. However, even with a loading dose, 2-3 days are required to reach a therapeutic plasma level of $20 \mathrm{mg} / \mathrm{L}$, making it less suitable for treating acute severe infection and more appropriate for long-term therapy (e.g. bone infection). Teicoplanin has the benefit of a lower propensity for nephrotoxicity than vancomycin [44], although this is dose-related. Therapeutic drug monitoring has a role for teicoplanin and appropriate facilities are less commonly available. Teicoplanin is $\geq 90 \%$ bound to plasma proteins $[46,47]$. However, it is not clear whether the bactericidal action of glycopeptides is related to the total concentration rather than the free concentration [47]. This uncertainty highlights the need for further research into the pharmacokinetics/pharmacodynamics of glycopeptides. 


\section{$14 / 05 / 2010$}

In conclusion, teicoplanin has a limited role for severe MRSA infections, namely when there is particular concern over nephrotoxicity.

\section{Linezolid}

Linezolid, the first available oxazolidinone antibacterial, has the advantages of a novel (albeit bacteriostatic) mechanism of action and $100 \%$ oral bioavailability. It rapidly achieves therapeutic plasma concentrations, has relatively low protein binding, is well distributed and has good activity against invasive MRSA [14,48]. Linezolid is associated with a lower risk of nephrotoxicity than vancomycin [49] but it can cause myelosuppression [50]. The standard twice-daily dose of linezolid may achieve suboptimal concentrations in some patients [51]. Use of thrice-daily dosing in complicated skin and skin-structure infections (cSSSIs) has been proposed, but limited data are available. Data from a small study in critically ill septic patients suggest that continuous infusion may provide superior PK/PD exposure over twicedaily infusion of the same daily dose [52].

Recent meta-analyses of randomised trials have found linezolid to be similarly effective as comparators in Gram-positive pneumonia [49,50]. Retrospective subgroup analysis of data from two double-blind, randomised trials suggest that linezolid gave significantly higher cure and survival rates than vancomycin in subgroups of patients with MRSA HAP $(n=161)$ [10] and VAP $(n=91)$ [11]. Results from a small prospective randomised study in Japan suggest that linezolid is as effective as vancomycin in patients with MRSA pneumonia (total $n=54$ ) [53]. The manufacturer of linezolid has completed a study of linezolid versus vancomycin in 
$14 / 05 / 2010$

patients with VAP (http://www.clinicaltrials.gov reference NCT00572559), whilst another study comparing these agents in patients with MRSA HAP is ongoing (NCT00084266).

There has been controversy over whether linezolid is suitable for $S$. aureus bacteraemia. Recent meta-analyses of randomised trials have found linezolid to be more effective [50] or similarly effective [49] as comparators in Gram-positive bacteraemia. However, an open-label study of linezolid versus vancomycin plus dicloxacillin (or oxacillin) in patients with intravascular catheter-related infection was prematurely terminated because of a higher mortality rate in the linezolid group [54]. This difference was due to higher mortality in linezolid recipients with Gram-negative infections, with both Gram-positive and Gram-negative infections, or with no infection. There was no difference between the mortality rates in patients with Grampositive infections alone. These result led to warnings against the use of linezolid for catheter-related bloodstream infections or catheter-site infections [54].

Although linezolid has maintained potent activity against Gram-positive pathogens $[14,55]$, at least one single-centre study has reported an increase in the modal MIC over time among MRSA [13]. Overt resistance to linezolid can occur via mutations in domain $\mathrm{V}$ of the $23 \mathrm{~S}$ rRNA gene of the $50 \mathrm{~S}$ ribosomal subunit $[56,57]$. Of particular concern is a report of plasmid-mediated resistance in one isolate of MRSA and one of Staphylococcus epidermidis [55,58]. In fact, an outbreak of linezolid- and meticillin-resistant $S$. aureus, mediated by the cfr gene, has been reported in an Intensive Care Unit in Spain, associated with nosocomial transmission and extensive usage of linezolid [59]. Reduction of linezolid usage and infection control measures 
$14 / 05 / 2010$

were associated with the termination of the outbreak [59]. Another outbreak of potentially transmissible linezolid resistance has been reported in Japan [60]. This mobile resistance element may also confer resistance to the novel topical pleuromutilins, e.g. retapamulin.

In conclusion, linezolid is a convenient option for use in suspected MRSA VAP and the results of current further studies are awaited. Specific recommendations regarding the use of linezolid with treatment approaches are summarised at the end of this article (Table 1).

\section{Daptomycin}

Daptomycin is a parenteral lipopeptide agent with a novel mechanism of action and potent activity against invasive MRSA [14]. Based on limited data, daptomycin is approved in Europe for right-side endocarditis and S. aureus bacteraemia. It is not effective in (or approved for) pneumonia therapy owing to its inactivation by lung surfactant.

In a prospective randomised trial, daptomycin was non-inferior to standard therapy (low-dose gentamicin plus either an antistaphylococcal penicillin or vancomycin) for S. aureus bacteraemia with or without right-sided IE [42]. In the subset of 88 patients with MRSA infections, daptomycin was at least as effective as gentamicin plus vancomycin [61]. Success rates for daptomycin versus vancomycin/gentamicin were $45 \%$ vs. $27 \%$ in complicated bacteraemia, $60 \%$ vs. $45 \%$ in uncomplicated bacteraemia and $50 \%$ vs. $50 \%$ in right-sided MRSA endocarditis. 
Evidence suggests that MICs for daptomycin correlate with vancomycin MICs tested at the initiation of vancomycin therapy in patients with MRSA bacteraemia and during therapy [62]. Thus, a switch to daptomycin should be made as early as possible once an elevated vancomycin MIC is confirmed, and should also be based on the daptomycin MIC. Daptomycin resistance, associated with changes in the structure and function of the bacterial cell membrane, has been reported and has resulted in treatment failure in patients with $S$. aureus infection [63-65]. The approved dose of daptomycin ( $6 \mathrm{mg} / \mathrm{kg}$ for endocarditis and bacteraemia) has been associated with the emergence of resistance [42]. As a result, the use of higher doses (10 mg/kg) has been proposed. Limited data suggest that this dose is not associated with increased toxicity $[66,67]$. However, this usage is off-label and further research is required to establish its safety and effect in preventing the emergence of resistance. One approach may be to start daptomycin at the higher dose and to reduce it if toxicity is suspected or if clinical improvement occurs, taking advantage of the concentration-dependent cidal action when the inoculum is highest.

Daptomycin was associated with a significantly reduced risk of decreased renal function than standard therapy with gentamicin-based therapy in the treatment of $S$. aureus bacteraemia and endocarditis [42]. Daptomycin has been used thrice-weekly in patients undergoing haemodialysis $[68,69]$.

In conclusion, daptomycin has an important role both in empirical and MIC-directed treatment of MRSA bacteraemia and endocarditis. Specific recommendations are made at the end of this article (Table 1 ). 


\section{Tigecycline}

Tigecycline is a novel parenteral glycylcycline antibacterial with activity against MRSA [70]. The panel were not aware of significant data published on the efficacy of tigecycline in the treatment of MRSA bacteraemia, VAP, HAP or endocarditis. Therefore, no recommendations could be provided and this agent is considered to have only a secondary 'rescue' role in this setting.

\section{Quinupristin/dalfopristin}

The panel were not aware of any significant new data published since the previous consensus report [6] and this agent is not recommended for use in severe MRSA infection, except as 'rescue' therapy.

\section{Older agents}

Data from a randomised study published in 1992 suggest that trimethoprim/sulfamethoxazole (co-trimoxazole) is inferior to vancomycin [41]. In principal, an increase in vancomycin MICs could change this situation. Data are awaited from an ongoing randomised, open-label study comparing co-trimoxazole and vancomycin in invasive MRSA infections in Israel (NCT00427076). In the meantime, the current panel was reluctant to recommend the use of co-trimoxazole alone in patients with severe MRSA infections. 
$14 / 05 / 2010$

There is no evidence to support a role for tetracyclines in severe MRSA infections [6]. Chloramphenicol has a role only as a last resort owing to its myelotoxicity and lack of recent clinical data [6]. Preliminary data suggest that fosfomycin may have a potential future role in combination with carbapenems in endocarditis [71], but further data are required. Rifampicin is not recommended alone or in combination for treatment of serious staphylococcal infection; there is evidence of delayed clearance of bacteraemia and increased hepatotoxicity. Its role is in combination therapy for medical treatment of infected prosthetics.

\section{Developmental agents}

Telavancin, a bactericidal lipoglycopeptide, is now approved in the USA for cSSSI and approval is expected in the European Union. In phase III trials, telavancin was as clinically and bacteriologically efficacious as vancomycin in the subset of patients with MRSA cSSSI $(n=579)$ [72]. Data from a completed randomised, double-blind trial of telavancin versus vancomycin in the treatment of uncomplicated $S$. aureus bacteraemia (NCT00062647) and two phase III studies in HAP (NCT00124020 and NCT00107952) are awaited.

In 2008, the manufacturer of dalbavancin (a lipoglycopeptide) withdrew their US and European applications for the indication of cSSSI [73]. The US Food and Drug Administration (FDA) has requested further data following the application for oritavancin (a semisynthetic glycopeptide) for a cSSSI indication. The European Medicines Agency (EMEA) also indicated that existing data were likely to be 
$14 / 05 / 2010$

insufficient to warrant the approval of oritavancin and in September 2009 the manufacturer withdrew its European application [74].

The FDA and EMEA have both denied a cSSSI indication for ceftobiprole, a novel cephalosporin, based on concerns about the conduct of studies and the need for further data $[75,76]$. Ceftobiprole was shown to be non-inferior to ceftazidime + linezolid in patients with HAP. However, ceftobiprole was less effective in the subset of patients with VAP, and non-inferiority versus the combination regimen could not be established [77]. Ceftaroline, a novel parenteral, semisynthetic cephalosporin, has high affinity for penicillin-binding protein PBP20 (PBP2a) and shows broadspectrum bactericidal activity that includes Gram-positive organisms as well as common Gram-negative pathogens. Ceftaroline is administered intravenously as a prodrug (ceftaroline fosamil) that is rapidly converted in plasma into the active drug. It has potent activity against community-associated MRSA isolates and showed bactericidal activity against VISA, VRSA, hVISA and daptomycin-non-susceptible $S$. aureus isolates [78]. Animal studies support ceftaroline as a promising therapeutic option for the treatment of severe MRSA infections, including osteomyelitis and endocarditis $[79,80]$. Ceftaroline has been evaluated for cSSSI in two identical phase III clinical trials. Globally, it achieved high clinical cure rates similar to those obtained with vancomycin + aztreonam, including in patients infected with MRSA (93.4\% vs. 94.3\%, respectively). Ceftaroline was well tolerated, with a safety profile consistent with the cephalosporin class [81].

The development of iclaprim (a selective diaminopyrimidine dihydrofolate inhibitor) has been suspended after an application for the cSSSI indication was withdrawn 
$14 / 05 / 2010$

from the EMEA [82]. New fluoroquinolones are in development for potential use in MRSA. However, there are concerns that these may have compromised MRSA activity. Data are awaited regarding the development of new oxazolidinone agents.

\section{General strategy and summary of recommendations}

\subsection{Assessment and testing}

The ESCMID/ISC panel continues to endorse the principles of therapy outlined in the previous consensus paper [6]. Identification of patients at high risk of hospitalacquired MRSA infection and the early and accurate diagnosis of infections are vital. Developments in these areas are discussed in the companion papers to this article $[83,84]$. Empirical therapy for suspected severe MRSA infections should be based primarily on the local prevalence and resistance profile of MRSA and on the risk factors and clinical characteristics present in individual patients. These include: the source and severity of infection; presence of co-morbid conditions; use of concurrent interventions (e.g. indwelling devices or haemodialysis); and use and response to previous antibiotic therapy. Patients with recurrent MRSA infection, or with a history of extended vancomycin exposure, should be considered at high risk of infection with MRSA for which vancomycin MIC values are elevated. Appropriate and aggressive empirical therapy is required for these patients. In the presence of an indwelling device or foreign body, it is crucial to consider the need for removal of potentially infected foreign bodies or for surgical debridement and drainage of necrotic areas or purulent collections. Rapid measures should be taken to culture the microorganism and to determine its antimicrobial susceptibility. Designations of sensitive/resistant 
$14 / 05 / 2010$

based on defined microbiological breakpoints are of limited usefulness for prescribers, and clinical laboratories must report MIC values. The (approximate twofold) discrepancy between vancomycin MICs determined by BMD and Etest may have important clinical implications and this discrepancy should be taken into account when interpreting susceptibility data. The existing evidence suggests that clinical breakpoints for vancomycin should be lowered, but there was no consensus among the panel on whether the new breakpoint should be $0.5 \mathrm{mg} / \mathrm{L}$ or $1.0 \mathrm{mg} / \mathrm{L}$ and whether this should be accepted as method-dependent.

\subsection{MRSA bacteraemia and endocarditis}

Vancomycin is the standard empirical therapy for MRSA bacteraemia and endocarditis, particularly for non-life threatening infection and infections caused by MRSA with a vancomycin MIC (by Etest) $\leq 1 \mathrm{mg} / \mathrm{L}$ (Table 1). Vancomycin should be dosed to achieve a trough plasma concentration of $15-20 \mathrm{mg} / \mathrm{L}$. Teicoplanin may be the preferred glycopeptide for use when there is a particular concern over nephrotoxicity. Empirical therapy in very sick patients with severe suspected MRSA infection needs to cover MSSA as well as MRSA. The panel believes that vancomycin does not provide sufficient MSSA cover in this setting and hence it should be combined with a semisynthetic penicillin when used for empirical therapy. However, further studies on the optimal therapy are required. The combination of vancomycin plus a semisynthetic penicillin may be preferred when endocarditis is suspected, but more research needs to be done on the interaction between these two classes. The panel does not recommend the routine use of combination therapy with vancomycin plus an aminoglycoside owing to the risk of nephrotoxicity [85]. 
The panel recommends switching to daptomycin if there is a poor response to vancomycin, complicated bacteraemia, relapse or breakthrough MRSA bacteraemia, or if the vancomycin MIC of the causative pathogen is reported at $>1 \mathrm{mg} / \mathrm{L}$ (Etest) or $>0.5 \mathrm{mg} / \mathrm{L}$ (BMD). Where an elevated vancomycin is reported, the daptomycin MIC should also be checked. Daptomycin should be considered for first-line, initial therapy in patients with life-threatening infection, renal impairment, previous glycopeptide use and when the vancomycin MIC is known to be $>1 \mathrm{mg} / \mathrm{L}$ or is suspected to be $>1 \mathrm{mg} / \mathrm{L}$ based on local surveillance data using Etest. Consideration should be given to dosing daptomycin at $10 \mathrm{mg} / \mathrm{kg}$ in this setting, although this dose is not approved. The evidence base for linezolid in bacteraemia remains weak and there have been warnings regarding its use for catheter-related bloodstream infections, for which it is not approved.

Treatment durations of 10-14 days are generally recommended for bacteraemia [6]. Treatment for 4-6 weeks is required in endocarditis and complicated bacteraemia. Additional studies are needed to determine the optimum duration of therapy for severe MRSA infections, including bacteraemia. Results from an ongoing study in the UK are awaited.

\subsection{MRSA hospital-acquired pneumonia and ventilator-associated pneumonia}

The panel supports the widespread current practice whereby linezolid is used firstline as empirical therapy for suspected MRSA VAP and HAP (e.g. in patients who tested positive for MRSA on admission). The results of current further studies are 
$14 / 05 / 2010$

awaited. In particular, linezolid may be preferred over vancomycin where there are concerns about nephrotoxicity and when the infecting MRSA has a vancomycin MIC $>1 \mathrm{mg} / \mathrm{L}$ by Etest. Linezolid may also be preferred because of convenience. Further high-quality randomised controlled trials of linezolid in MRSA infections are needed. In fact in a recent presentation at this year's IDSA Annual Meeting, the first report of a phase IV, randomised, double-blind, multicentre trial comparing linezolid with vancomycin in nosocomial pneumonia due to proven MRSA, linezolid was statistically superior at end of therapy and end of study, both in intent-to-treat and modified intent-to-treat for both clinical and microbiological outcomes [86].

Durations of 10-14 days are generally recommended for HAP and VAP. Linezolid should also offer sufficient cover for pneumonia caused by MRSA positive for the Panton-Valentine leukocidin cytotoxin. However, recommendations are limited by a lack of experience and data.

\section{Funding}

This review would not have been possible without unrestricted educational grants from Novartis, Astellas, Wyeth, Becton Dickinson, bioMérieux and Cepheid that were used to finance the meeting and to pay for writing support. All the authors have received financial support from companies manufacturing diagnostics and therapeutics for MRSA.

\section{Competing interests}

This review would not have been possible without unrestricted educational grants from Novartis, Astellas, Wyeth, Becton Dickinson, bioMérieux and Cepheid that were 
$14 / 05 / 2010$

used to finance the meeting and to pay for writing support. All the authors have received financial support from companies manufacturing diagnostics and therapeutics for MRSA.

\section{Ethical approval}

Not required. 


\section{References}

[1] European Antimicrobial Resistance Surveillance System Annual Report, 2008. Bilthoven, The Netherlands: National Institute for Public Health and the Environment; 2009.

[2] Cosgrove SE, Sakoulas G, Perencevich EN, Schwaber MJ, Karchmer AW, Carmeli Y. Comparison of mortality associated with methicillin-resistant and methicillin-susceptible Staphylococcus aureus bacteremia: a meta-analysis. Clin Infect Dis 2003;36:53-9.

[3] Melzer M, Eykyn SJ, Gransden WR, Chinn S. Is methicillin-resistant Staphylococcus aureus more virulent than methicillin-susceptible S. aureus? A comparative cohort study of British patients with nosocomial infection and bacteremia. Clin Infect Dis 2003;37:1453-60.

[4] Shurland S, Zhan M, Bradham DD, Roghmann MC. Comparison of mortality risk associated with bacteremia due to methicillin-resistant and methicillin-susceptible Staphylococcus aureus. Infect Control Hosp Epidemiol 2007;28:273-9.

[5] Athanassa Z, Siempos II, Falagas ME. Impact of methicillin resistance on mortality in Staphylococcus aureus VAP: a systematic review. Eur Respir J $2008 ; 28: 625-32$.

[6] Garau J, Bouza E, Chastre J, Gudiol F, Harbarth S. Management of methicillinresistant Staphylococcus aureus infections. Clin Microbiol Infect 2009;15:125-36.

[7] Hussain A, Alleyne S, Jenkins D. A survey of attitudes towards methicillinresistant Staphylococcus aureus bacteraemias amongst United Kingdom microbiologists. J Antimicrob Chemother 2010;65:347-9. 
[8] Deresinski S. Counterpoint: Vancomycin and Staphylococcus aureus-an antibiotic enters obsolescence. Clin Infect Dis 2007;44:1543-8.

[9] Mohr JF, Murray BE. Point: Vancomycin is not obsolete for the treatment of infection caused by methicillin-resistant Staphylococcus aureus. Clin Infect Dis 2007;44:1536-42.

[10] Wunderink RG, Rello J, Cammarata SK, Croos-Dabrera RV, Kollef MH. Linezolid vs vancomycin: analysis of two double-blind studies of patients with methicillin-resistant Staphylococcus aureus nosocomial pneumonia. Chest 2003;124:1789-97.

[11] Kollef MH, Rello J, Cammarata SK, Croos-Dabrera RV, Wunderink RG. Clinical cure and survival in Gram-positive ventilator-associated pneumonia: retrospective analysis of two double-blind studies comparing linezolid with vancomycin. Intensive Care Med 2004;30:388-94.

[12] Wang G, Hindler JF, Ward KW, Bruckner DA. Increased vancomycin MICs for Staphylococcus aureus clinical isolates from a university hospital during a 5-year period. J Clin Microbiol 2006;44:3883-6.

[13] Steinkraus G, White R, Friedrich L. Vancomycin MIC creep in nonvancomycin-intermediate Staphylococcus aureus (VISA), vancomycinsusceptible clinical methicillin-resistant $S$. aureus (MRSA) blood isolates from 2001-05. J Antimicrob Chemother 2007;60:788-94.

[14] Holmes RL, Jorgensen JA. Inhibitory activities of 11 antimicrobial agents and bactericidal activities of vancomycin and daptomycin against invasive methicillinresistant Staphylococcus aureus isolates obtained from 1999 through 2006. Antimicrob Agents Chemother 2008;52:757-60. 
[15] Hope R, Livermore DM, Brick G, Lillie M, Reynolds R; BSAC Working Parties on Resistance Surveillance. Non-susceptibility trends among staphylococci from bacteraemias in the UK and Ireland, 2001-06. J Antimicrob Chemother 2008;62(Suppl 2):ii65-74.

[16] Prakash V, Lewis JS 2nd, Jorgensen JH. Vancomycin MICs for methicillinresistant Staphylococcus aureus isolates differ based upon the susceptibility test method used. Antimicrob Agents Chemother 2008;52:4528.

[17] Sader HS, Rhomberg PR, Jones RN. Nine-hospital study comparing broth microdilution and E-test method results for vancomycin and daptomycin against methicillin-resistant Staphylococcus aureus. Antimicrob Agents Chemother 2009;53:3162-5.

[18] Horne KC, Howden BP, Grabsch EA, Graham M, Ward PB, Xie S, et al. Prospective comparison of the clinical impacts of heterogeneous vancomycinintermediate methicillin-resistant Staphylococcus aureus (MRSA) and vancomycin-susceptible MRSA. Antimicrob Agents Chemother 2009;53:3447-52.

[19] Bae IG, Federspiel JJ, Miró JM, Woods CW, Park L, Rybak MJ, et al. Heterogeneous vancomycin-intermediate susceptibility phenotype in bloodstream methicillin-resistant Staphylococcus aureus isolates from an international cohort of patients with infective endocarditis: prevalence, genotype, and clinical significance. J Infect Dis 2009;200:1355-66.

[20] Maor Y, Hagin M, Belausov N, Keller N, Ben-David D, Rahav G. Clinical features of heteroresistant vancomycin-intermediate Staphylococcus aureus bacteremia versus those of methicillin-resistant $S$. aureus bacteremia. J Infect Dis 2009;199:619-24. 
[21] Charles PG, Ward PB, Johnson PD, Howden BP, Grayson ML. Clinical features associated with bacteremia due to heterogeneous vancomycinintermediate Staphylococcus aureus. Clin Infect Dis 2004;38:448-51.

[22] Howden BP, Ward PB, Charles PG, Korman TM, Fuller A, du Cros P, et al. Treatment outcomes for serious infections caused by methicillin-resistant Staphylococcus aureus with reduced vancomycin susceptibility. Clin Infect Dis $2004 ; 38: 521-8$.

[23] Alós JI, García-Cañas A, García-Hierro P, Rodríguez-Salvanés F. Vancomycin MICs did not creep in Staphylococcus aureus isolates from 2002 to 2006 in a setting with low vancomycin usage. J Antimicrob Chemother 2008;62:773-5.

[24] Gasch GO, Ayats J, Dominguez MA, et al. Secular trends in the epidemiology of methicillin-resistant Staphylococcus aureus (MRSA) bacteremia in a university hospital. In: 49th Interscience Conference on Antimicrobial Agents and Chemotherapy (ICAAC); 12-15 September 2009; San Francisco, CA. Washington, DC: ASM Press; 2009. Abstract K-1630.

[25] Jones RN. Microbiological features of vancomycin in the 21st century: minimum inhibitory concentration creep, bactericidal/static activity, and applied breakpoints to predict clinical outcomes or detect resistant strains. Clin Infect Dis 2006;42(Suppl 1):S13-24.

[26] Moise PA, Smyth DS, El-Fawal N, Robinson DA, Holden PN, Forrest A, et al. Microbiological effects of prior vancomycin use in patients with methicillinresistant Staphylococcus aureus bacteraemia. J Antimicrob Chemother 2008;61:85-90. 
[27] Moise-Broder P, El-Fawal N, Forrest A, et al. Relationship of prior vancomycin use and daptomycin MICs in patients with MRSA bacteremia. In: 46th Interscience Conference on Antimicrobial Agents and Chemotherapy (ICAAC); 27-30 September 2006; San Francisco, CA. Washington, DC: ASM Press; 2006. Abstract C2-1151.

[28] Clinical and Laboratory Standards Institute. Methods for dilution antimicrobial susceptibility tests for bacteria that grow aerobically; approved standard. 7th ed. Document M7-A7. Wayne, PA: CLSI; 2006.

[29] European Committee on Antimicrobial Susceptibility Testing. Breakpoint tables for interpretation of MICs and zone diameters, version 1.0. Basel, Switzerland: EUCAST; 2009.

[30] Moise-Broder PA, Forrest A, Birmingham MC, Schentag JJ. Pharmacodynamics of vancomycin and other antimicrobials in patients with Staphylococcus aureus lower respiratory tract infections. Clin Pharmacokinet 2004;43:925-42.

[31] Sakoulas G, Moise-Broder PA, Schentag J, Forrest A, Moellering RC Jr, Eliopoulos GM. Relationship of MIC and bactericidal activity to efficacy of vancomycin for treatment of methicillin-resistant Staphylococcus aureus bacteremia. J Clin Microbiol 2004;42:2398-402.

[32] Hidayat LK, Hsu DI, Quist R, Shriner KA, Wong-Beringer A. High-dose vancomycin therapy for methicillin-resistant Staphylococcus aureus infections: efficacy and toxicity. Arch Intern Med 2006;166:2138-44.

[33] Moise PA, Sakoulas G, Forrest A, Schentag JJ. Vancomycin in vitro bactericidal activity and its relationship to efficacy in clearance of methicillin- 
resistant Staphylococcus aureus bacteremia. Antimicrob Agents Chemother $2007 ; 51: 2582-6$.

[34] Lodise TP, Graves J, Evans A, Graffunder E, Helmecke M, Lomaestro BM, et al. Relationship between vancomycin MIC and failure among patients with methicillin-resistant Staphylococcus aureus bacteremia treated with vancomycin. Antimicrob Agents Chemother 2008;52:3315-20.

[35] Soriano A, Marco F, Martínez JA, Pisos E, Almela M, Dimova VP, et al. Influence of vancomycin minimum inhibitory concentration on the treatment of methicillin-resistant Staphylococcus aureus bacteremia. Clin Infect Dis 2008;46:193-200.

[36] Hsu DI, Hidayat LK, Quist R, Hindler J, Karlsson A, Yusof A, et al. Comparison of method-specific vancomycin minimum inhibitory concentration values and their predictability for treatment outcome of meticillin-resistant Staphylococcus aureus (MRSA) infections. Int J Antimicrob Agents 2008;32:37885.

[37] Rybak MJ, Lomaestro BM, Rotscahfer JC, Moellering RC, Craig WA, Billeter $M$, et al. Vancomycin therapeutic guidelines: a summary of consensus recommendations from the Infectious Diseases Society of America, the American Society of Health-System Pharmacists, and the Society of Infectious Diseases Pharmacists. Clin Infect Dis 2009;49:325-7.

[38] Jeffres MN, Isakow W, Doherty JA, McKinnon PS, Ritchie DJ, Micek ST, et al. Predictors of mortality for methicillin-resistant Staphylococcus aureus healthcare-associated pneumonia: specific evaluation of vancomycin pharmacokinetic indices. Chest 2006;130:947-55. 
[39] Lodise TP, Patel N, Lomaestro BM, Rodvold KA, Drusano GL. Relationship between initial vancomycin concentration-time profile and nephrotoxicity among hospitalized patients. Clin Infect Dis 2009;49:507-14.

[40] Lodise TP, Lomaestro B, Graves J, Drusano GL. Larger vancomycin doses (at least four grams per day) are associated with an increased incidence of nephrotoxicity. Antimicrob Agents Chemother 2008;52:1330-6.

[41] Markowitz N, Quinn EL, Saravolatz LD. Trimethoprim-sulfamethoxazole compared with vancomycin for the treatment of Staphylococcus aureus infection. Ann Intern Med 1992;117:390-8.

[42] Fowler VG, Boucher HW, Corey GR, Abrutyn E, Karchmer AW, Rupp ME, et al. Daptomycin versus standard therapy for bacteremia and endocarditis caused by Staphylococcus aureus. N Engl J Med 2006;355:653-65.

[43] Kollef MH, Napolitano LM, Solomkin JS, Wunderink RG, Bae IG, Fowler VG, et al. Health care-associated infection (HAl): a critical appraisal of the emerging threat-Proceedings of the HAI Summit. Clin Infect Dis 2008;47(Suppl 2):S5599.

[44] Svetitsky S, Leibovici L, Paul M. Comparative efficacy and safety of vancomycin versus teicoplanin: systematic review and meta-analysis. Antimicrob Agents Chemother 2009;53:4069-79.

[45] Kirby A, Graham R, Williams NJ, Wootton M, Broughton CM, Alanazi M, et al. Staphylococcus aureus with reduced glycopeptide susceptibility in Liverpool, UK. J Antimicrob Chemother 2010;65:721-4.

[46] Wilson AP. Clinical pharmacokinetics of teicoplanin. Clin Pharmacokinet 2000;39:167-83. 
[47] Dykhuizen RS, Harvey G, Stephenson N, Nathwani D, Gould IM. Protein binding and serum bactericidal activities of vancomycin and teicoplanin. Antimicrob Agents Chemother 1995;39:1842-7.

[48] Stalker DJ, Jungbluth GL. Clinical pharmacokinetics of linezolid, a novel oxazolidinone antibacterial. Clin Pharmacokinet 2003;42:1129-40.

[49] Beibei L, Yun C, Mengli C, Nan B, Xuhong Y, Rui W. Linezolid versus vancomycin for the treatment of Gram-positive bacterial infections: meta-analysis of randomised controlled trials. Int J Antimicrob Agents 2010;35:3-12.

[50] Falagas ME, Siempos II, Vardakas KZ. Linezolid versus glycopeptide or $\beta$ lactam for treatment of Gram-positive bacterial infections: meta-analysis of randomised controlled trials. Lancet Infect Dis 2008;8:53-66.

[51] Goldstein FW, Zeller V, Desplaces N, Kitzis MD. Linezolid (Lin) serum levels: one size doesn't fit all! In: 46th Interscience Conference on Antimicrobial Agents and Chemotherapy (ICAAC); 27-30 September 2006; San Francisco, CA.

Washington, DC: ASM Press; 2006. Abstract A1945.

[52] Adembri C, Fallani S, Cassetta MI, Arrigucci S, Ottaviano A, Pecile P, et al. Linezolid pharmacokinetic/pharmacodynamic profile in critically ill septic patients: intermittent versus continuous infusion. Int J Antimicrob Agents 2008;31:122-9.

[53] Kohno S, Yamaguchi K, Aikawa N, Sumiyama Y, Odagiri S, Aoki N, et al. Linezolid versus vancomycin for the treatment of infections caused by methicillinresistant Staphylococcus aureus in Japan. J Antimicrob Chemother 2007;60:1361-9.

[54] US Food and Drug Administration. Information for healthcare professionals: linezolid (marketed as Zyvox). Silver Spring, MD: FDA; 16 March 2007. 
[55] Jones RN, Ross JE, Castanheira M, Mendes RE. United States resistance surveillance results for linezolid (LEADER Program for 2007). Diagn Microbiol Infect Dis 2008;62:416-26.

[56] Long KS, Poehlsgaard J, Kehrenberg C, Schwarz S, Vester B. The Cfr rRNA methyltransferase confers resistance to phenicols, lincosamides, oxazolidinones, pleuromutilins, and streptogramin A antibiotics. Antimicrob Agents Chemother $2006 ; 50: 2500-5$.

[57] Arias CA, Vallejo M, Reyes J, Panesso D, Moreno J, Castañeda E, et al. Clinical and microbiological aspects of linezolid resistance mediated by the cfr gene encoding a 23S rRNA methyltransferase. J Clin Microbiol 2008;46:892-6.

[58] Mendes RE, Deshpande LM, Castanheira M, DiPersio J, Saubolle MA, Jones RN. First report of cfr-mediated resistance to linezolid in human staphylococcal clinical isolates recovered in the United States. Antimicrob Agents Chemother 2008;52:2244-6.

[59] Sánchez García M, De la Torre MA, Morales G, Peláez B, Tolón MJ, Domingo S, et al. Clinical outbreak of linezolid-resistant Staphylococcus aureus in an intensive care unit. JAMA 2010;303:2260-4.

[60] Yoshida K, Shoji H, Hanaki H, Yanagisawa C, Ikeda-Dantsuji Y, Fukuchi K, et al. Linezolid-resistant methicillin-resistant Staphylococcus aureus isolated after long-term, repeated use of linezolid. J Infect Chemother 2009;15:417-9.

[61] Rehm SJ, Boucher H, Levine D, Campion M, Eisenstein BI, Vigliani GA, et al. Daptomycin versus vancomycin plus gentamicin for treatment of bacteraemia and endocarditis due to Staphylococcus aureus: subset analysis of patients infected with methicillin-resistant isolates. J Antimicrob Chemother 2008;62:1413-21. 
[62] Patel N, Lubanski P, Ferro S, Bonafede M, Harrington S, Evans A, et al. Correlation between vancomycin MIC values and those of other agents against Gram-positive bacteria among patients with bloodstream infections caused by methicillin-resistant Staphylococcus aureus. Antimicrob Agents Chemother $2009 ; 53: 5141-4$.

[63] Hayden MK, Rezai K, Hayes RA, Lolans K, Quinn JP, Weinstein RA. Development of daptomycin resistance in vivo in methicillin-resistant Staphylococcus aureus. J Clin Microbiol 2005;43:5285-7.

[64] Jones T, Yeaman MR, Sakoulas G, Yang SJ, Proctor RA, Sahl HG, et al. Failures in clinical treatment of Staphylococcus aureus infection with daptomycin are associated with alterations in surface charge, membrane phospholipid asymmetry, and drug binding. Antimicrob Agents Chemother 2008;52:269-78.

[65] Mishra NN, Yang SJ, Sawa A, Rubio A, Nast CC, Yeaman MR, et al. Analysis of cell membrane characteristics of in vitro-selected daptomycin-resistant strains of methicillin-resistant Staphylococcus aureus. Antimicrob Agents Chemother 2009;53:2312-8.

[66] Benvenuto M, Benziger DP, Yankelev S, Vigliani G. Pharmacokinetics and tolerability of daptomycin at doses up to 12 milligrams per kilogram of body weight once daily in healthy volunteers. Antimicrob Agents Chemother 2006;50:3245-9.

[67] Moise PA, Hershberger E, Amodio-Groton MI, Lamp KC. Safety and clinical outcomes when utilizing high-dose ( $\geq 8 \mathrm{mg} / \mathrm{kg}$ ) daptomycin therapy. Ann Pharmacother 2009;43:1211-9. 
[68] Burkhardt O, Kielstein JT. A simplified three-times weekly daptomycin dosing regimen for chronic hemodialysis patients. Expert Rev Anti Infect Ther 2010;8:11-4.

[69] Salama NN, Segal JH, Churchwell MD, Patel JH, Gao L, Heung M, et al. Single-dose daptomycin pharmacokinetics in chronic haemodialysis patients. Nephrol Dial Transplant 2010;25:1279-84.

[70] Putnam SD, Sader HS, Farrell DJ, Jones RN. Sustained antimicrobial activity of tigecycline against methicillin-resistant Staphylococcus aureus (MRSA) from United States medical centers from 2004 through 2008. J Chemother $2010 ; 22: 13-6$.

[71] Míro JM, del Río A, Moreno A, et al. Efficacy and safety of fosfomycin (F) plus imipenem (I) for the treatment of methicillin-resistant Staphylococcus aureus (MRSA) native valve endocarditis (NVE): preliminary results of a clinical trial. In: 48th Interscience Conference on Antimicrobial Agents and Chemotherapy (ICAAC); 25-28 October 2008; Washington, DC. Washington, DC: ASM Press; 2008.

[72] Stryjewski ME, Graham DR, Wilson SE, O'Riordan W, Young D, Lentnek A, et al. Telavancin versus vancomycin for the treatment of complicated skin and skinstructure infections caused by Gram-positive organisms. Clin Infect Dis 2008;46:1683-93.

[73] Pfizer Inc. Pfizer will withdraw global marketing applications for dalbavancin to conduct a new trial. Pfizer press release. 9 September 2008 http://www.businesswire.com/portal/site/pfizer/permalink/?ndmViewld=news_view \&newsld=20080909005943\&newsLang=en [accessed 30 November 2010]. 
[74] European Medicines Agency. Questions and answers on the withdrawal of the marketing authorisation application for Ramvocid (oritavancin).

EMEA/554626/2009. London, UK: EMEA; 24 September 2009.

[75] Johnson \& Johnson. FDA issues complete response letter for ceftobiprole.

Press release. 30 December 2009. Raritan, NJ: Johnson \& Johnson; 2009 http://www.jnj.com/connect/news/all/20091230_090000 [accessed 10 May 2010].

[76] European Medicines Agency. Questions and answers: refusal of the marketing approval for Zeftera (ceftobiprole). EMA/83783/2010. London, UK: EMEA; 18 February 2010.

[77] Noel GJ, Strauss RS, Shah A, Bagchi P; BAP00248/307 Study Group. Ceftobiprole versus ceftazidime combined with linezolid for treatment of patients with nosocomial pneumonia. In: Interscience Conference on Antimicrobial Agents and Chemotherapy (ICAAC); 25-28 October 2008; Washington, DC.

Washington, DC: ASM Press; 2008. Abstract K-486.

[78] Saravolatz L, Pawlak J, Johnson L. In vitro activity of ceftaroline against community-associated methicillin-resistant, vancomycin-intermediate, vancomycin-resistant, and daptomycin-nonsusceptible Staphylococcus aureus isolates. Antimicrob Agents Chemother 2010;54:3027-30.

[79] Jacqueline C, Amador G, Caillon J, Le Mabecque V, Batard E, Miègeville_AF, et al. Efficacy of the new cephalosporin ceftaroline in the treatment of experimental methicillin-resistant Staphylococcus aureus acute osteomyelitis. J Antimicrob Agents 2010;65:1749-52.

[80] Jacqueline C, Caillon J, Batard E, Le Mabecque V, Amador G, Ge Y, et al. Evaluation of the in vivo efficacy of intramuscularly administered ceftaroline fosamil, a novel cephalosporin, against a methicillin-resistant Staphylococcus 
aureus strain in a rabbit endocarditis model. J Antimicrob Agents 2010;65:22645.

[81] Corey GR, Wilcox M, Talbot GH, Friedland HD, Baculik T, Witherell GW, et al. Integrated analysis of CANVAS 1 and 2: phase 3, multicenter, randomized, double-blind studies to evaluate the safety and efficacy of ceftaroline versus vancomycin plus aztreonam in complicated skin and skin-structure infection. Clin Infect Dis 2010;51:641-50.

[82] Arpida. Arpida withdraws European marketing application for intravenous iclaprim in cSSTI as a result of negative outcome of CHMP hearing. Press release 20 October 2009. Reinach, Switzerland: Evolva/Arpida; 2009. http:www.evolva.com/newsroom/2009/10/20/53/arpida-withdraws-europeanmarketing-application-intravenous-iclaprim-cssti-re [accessed 1 May 2010].

[83] Harbarth S, Hawkey PM, Tenover F, Stefani S, Pantosti A, Struelens MJ. Update on screening and clinical diagnosis of meticillin-resistant Staphylococcus aureus. Int J Antimicrob Agents [IJAA-D-10-00805 - update details]

[84] Rome Paper 2. Int J Antimicrob Agents [Rome paper — details to be added]

[85] Cosgrove SE, Vigliani GA, Fowler VG, Abrutyn E, Corey GR, Levine DP, et al. Initial low-dose gentamicin for Staphylococcus aureus bacteremia and endocarditis is nephrotoxic. Clin Infect Dis 2009;48:713-21.

[86] Kunkel M, Chastre JE, Kollef M, Niederman M, Shorr AF, Wunderink RG, et al. Linezolid vs vancomycin in the treatment of nosocomial pneumonia proven due to methicillin-resistant Staphylococcus aureus. In: 48th Annual Meeting of the Infectious Diseases Society of America (IDSA), 21-24 October 2010; Vancouver, British Columbia, Canada. Abstract 5047. 
$14 / 05 / 2010$

\section{Table 1}

Treatment guidelines for severe meticillin-resistant Staphylococcus aureus (MRSA) infections $^{a, b}$

\begin{tabular}{|c|c|c|}
\hline $\begin{array}{l}\text { MRSA } \\
\text { infection }\end{array}$ & First-line therapy & Second-line/alternative therapy \\
\hline $\begin{array}{l}\text { Bacteraemia } \\
\text { /endocarditis }\end{array}$ & $\begin{array}{l}\text { EMPIRICAL THERAPY } \\
\text { Vancomycin: standard option for } \\
\text { initial treatment, in particular } \\
\text { when: } \\
\text { - sepsis is not life- } \\
\text { threatening }{ }^{\mathrm{c}} \\
\text { - MIC } \leq 1 \mathrm{mg} / \mathrm{L} \text { or unknown } \\
\text { Add semisynthetic penicillin to } \\
\text { cover MSSA in severe sepsis } \\
\text { Daptomycin preferred for first-line } \\
\text { initial therapy when: } \\
\text { - } \text { sepsis is life-threatening } \\
\text { - } \text { renal impairment } \\
\text { - glycopeptide MIC > } 1.0 \\
\text { mg/L } \\
\text { - previous optimally } \\
\text { conducted glycopeptide } \\
\text { therapy (check } \\
\text { daptomycin MIC) }\end{array}$ & $\begin{array}{l}\text { Change to daptomycin }{ }^{\mathrm{d}} \text { if: } \\
\text { - } \text { slow response } \\
\text { - complicated } \\
\text { bacteraemia, relapse or } \\
\text { breakthrough MRSA } \\
\text { bacteraemia } \\
\text { - MIC > } 1.0 \mathrm{mg} / \mathrm{L} \\
\text { Check daptomycin MIC if } \\
\text { patient has had previous } \\
\text { glycopeptide exposure }\end{array}$ \\
\hline
\end{tabular}




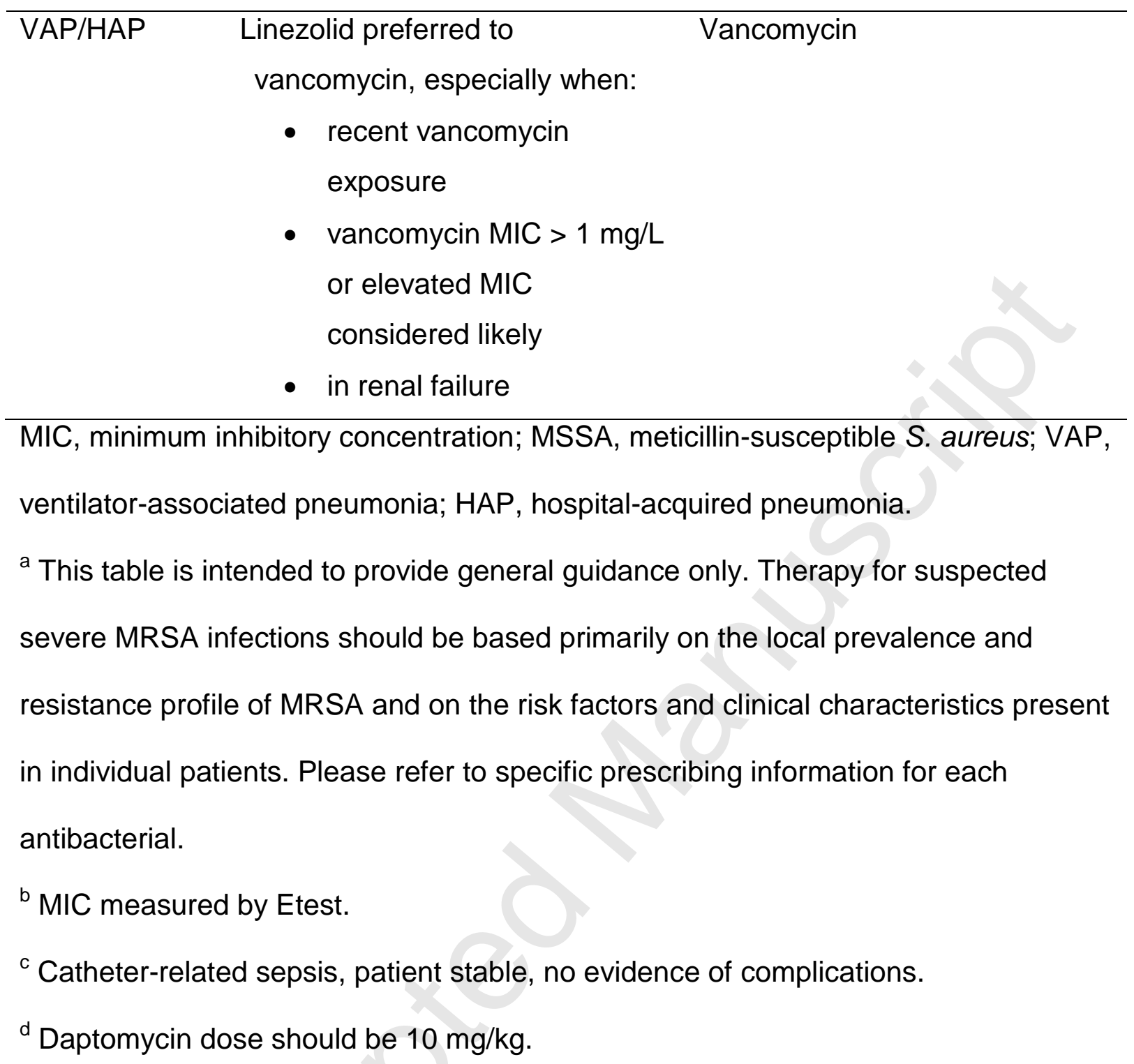

